\title{
ПЕРЕХОД ВО ВЗРОСЛУЮ ЖИЗНЬ: СРАВНЕНИЕ СЕВЕРНОГО КАВКАЗА С ОБЩЕРОССИЙСКОЙ КАРТИНОЙ
}

\begin{abstract}
Статья представляет анализ количественных данных, касающихся специфики процесса взросления индивида на Северном Кавказе. Исследование построено на материале общероссийского репрезентативного обследования «Человек, семья, общество», проведенного в 2013 г. В фокус наблюдения попали поколения 1970-1994 гг. рождения. Мы сравнили наступление событий, маркирующих взросление у жителей северокавказских республик с регионами России по следующим характеристикам: по частоте, возрасту, интенсивности и последовательности наступления событий. События, маркирующие взросление, разбиты на две группы: социодемографические (первая интимная близость, первое партнерство, первый брак и первое деторождение) и социоэкономические (завершение получения образования, первое отделение от родителей и первое трудоустройство). Показано, что на Северном Кавказе сохраняются более традиционные модели перехода во взрослую жизнь, нежели в остальных российских регионах: события в брачной и репродуктивной сферах наступают с более короткими интервалами, то есть сильно обуславливают друг друга; браки остаются превалирующей формой совместного проживания; деторождение происходит в более раннем возрасте и интенсивнее, чем в других регионах; гендерные различия в социодемографическом поведении почти отсутствуют, а в социально-экономическом- выражены сильнее, чем в других регионах. Тем не менее, представленные данные указывают и на некоторые признаки демографической модернизации. Так, у молодых северокавказских мужчин (но не у женщин) наблюдается большее по сравнению с предшествующими поколениями разнообразие в последовательности событий, связанных с взрослением, то есть единая для всех норма заменяется разнообразием жизненных путей.
\end{abstract}

Ключевые слова: взросление, брачность, рождаемость, образование, трудоустройство

DOI: $10.17323 / 727-0634-2019-17-1-133-141$

В статье представлены данные, позволяющие сопоставить население Северного Кавказа с населением других регионов России по характеристикам событий жизненного пути, маркирующих взросление: по частоте,

Екатерина Сергеевна Митрофанова- магистр социологии, младший научный сотрудник Института демографии, преподаватель кафедры демографии, Национальный Исследовательский Университет «Высшая Школа Экономики», Москва, Россия. Электронная почта: emitrofanova@hse.ru 
возрасту, интенсивности и последовательности их наступления. К событиям, маркирующим взросление, можно отнести социодемографические (первая интимная близость, первое партнерство, первый брак и первое деторождение) и социоэкономические (завершение получения образования, первое отделение от родителей и первое трудоустройство) (Billari et al. 2005; Billari, Liefbroer 2010; Buchmann 1989; Liefbroer 1999). Так как все эти события (кроме получения образования) являются первыми в той или иной сфере жизни, маркируя начало взрослой жизни, то для краткости будем называть их «стартовыми». Специфика процесса взросления определяется многими экономическими и культурными особенностями социума, к которому принадлежит индивид (Buchmann 1989; Elder et al. 2003; Esping-Andersen, 2007). Учет этой специфики, в том числе на уровне регионов, необходим для прогнозирования динамики брачности, рождаемости и различных аспектов социальной стратификации населения, в том числе в интересах планирования социальной политики.

Относительно регионов Северного Кавказа часто высказываются предположения, что наступление стартовых событий там отражает бо́льшую по сравнению с другими регионами России сохранность традиционных семейных норм (Лыткина 2010; Хубиев 2008). Особенности традиционного демографического поведения (Каа 1987; Вишневский 2006) позволяют сформулировать следующие гипотезы относительно поведения жителей Северного Кавказа. Во-первых, ожидаются значительные различия между мужчинами и женщинами по частоте, возрасту, интенсивности и последовательности наступления стартовых событий. Например, у женщин ожидается более ранний брак и меньшая активность на рынке труда, чем у мужчин. Во-вторых, ожидается меньший по сравнению с обществами иных укладов интервал между вступлением в брак и рождением первого ребенка, так как деторождение рассматривается в традиционном обществе как практически обязательный элемент супружеской жизни. Наконец, традиционный семейный уклад задает жесткую последовательность биографических событий, которая мало варьируется.

Для того, чтобы определить, насколько эти гипотезы верны, мы сопоставим данные выборочных опросов по Северному Кавказу и по другим регионам России. На сегодняшний момент есть несколько репрезентативных обследований, в которых собрана информация о датах наступления событий, маркирующих взросление, и регионе проживания. Самое свежее- это обследование «Человек, семья, общество» (ЧСО). Мы использовали только подвыборку респондентов, которым задавались вопросы обо всех стартовых событиях их жизненного пути. Полученная подвыборка является репрезентативной, т.к. получена из репрезентативной выборки. Для того, чтобы минимизировать возможные смещения, рассматривались все показатели в разрезе большого числа переменных. В подвыборку вошло 4367 человек (49\% мужчин, 51\% женщин) 1970-1994 г.р. Из них жителей Северного 
Кавказа- 282 человек (134 мужчины и 148 женщин), жителей других регионов России- 4085 человек (2004 мужчины и 2081 женщина). Горожанами являются $18 \%$ респондентов Северного Кавказа и $42 \%$ респондентов из остальных регионов; жителями поселков городского типа- $35 \%$ и $37 \%$ соответственно, жителями села $-47 \%$ и $21 \%$ соответственно.

Приводятся данные обследования по пяти пятилетним поколениям. Самым старшим (поколению 1970-1974 г.р.) на момент распада СССР было от 17 до 21 года; поколению 1975-1979 г.р.- 12-16 лет; поколению 19801984 г.р. - 7-11 лет. Все три поколения можно назвать переходными. Часть их первичной социализации прошла в СССР, но вступление во взрослую жизнь они начали уже в новой стране. Два самых молодых поколения (те, кто родился между 1985 и 1994 гг.) советского времени практически не застали, т.к. даже в школу пошли уже после того, как СССР распался.

В обследовании ЧСО были заданы вопросы о восьми стартовых событиях. Отраженные в опросе социодемографические события включают первую интимную близость, первое партнерство, первый брак, первое деторождение. Социально-экономические события включают окончание школы, завершение получения образования наивысшего для респондента уровня, первое отделение от родителей, первое трудоустройство. Под партнерством подразумевался незарегистрированный союз, длящийся как минимум три месяца и предполагающий совместное проживание партнеров. Отделение от родителей-проживание отдельно от них в течение минимум трех месяцев. Первая работа-работа без перерыва минимум шесть месяцев (подработки во время каникул и работа на неполный день не учитывались). Завершение образования является не стартовым, а заключительным событием для образовательной траектории, но т.к. мы рассматриваем не отдельные траектории, а взросление в целом, то для него завершение образования играет стартовую роль, открывая возможности для выхода на рынок труда.

Данные приводятся в трех разрезах: регион, пол, поколение. Различия по типу населенного пункта, уровню образования, религиозности и другим переменным не учитывались, т.к. в таком случае число респондентов в каждой категории для Северного Кавказа было бы слишком маленьким. Если оказывалось, что какое-либо из стартовых событий среди респондентов определенного пола, поколения и региона наступило менее чем для десяти человек, в таблицах ниже характеристики данного события для такой группы помечалось звездочкой и делались выводы относительно этих характеристик с осторожностью.

\section{Частота и интенсивность наступления событий}

Начнем анализ с характеристики частоты и интенсивности наступления событий. Частота наступления событий нами оценивается через долю респондентов, у которых на момент опроса наступило исследуемое событие 
(табл. 1)1. Для проверки статистической значимости различий мы использовали критерий хи-квадрат.

Региональные различия (без учета гендерной и межпоколенной разницы) между северокавказскими респондентами и респондентами из других частей России значимы более чем на 99-процентном уровне для интимной близости, партнерства, брака, трудоустройства и как минимум на 90-процентном уровне - для отделения от родителей, окончания школы и образования. Незначимы оказались только различия в деторождении. За исключением указанного события, на Северном Кавказе доли респондентов, у которых наступило то или иное стартовое событие, значимо ниже, чем в других регионах России. Разрыв, в среднем, составляет 5-14\% (интимная близость, брак, отделение, трудоустройство), но для партнерств достигает $30 \%$. Небольшая доля внебрачных партнерств и откладывание сексуального дебюта (видимо, до брака) свидетельствуют о более традиционном демографическом поведении на Северном Кавказе, нежели в других регионах России. На этот же контраст указывает и преобладание в других регионах России доли молодежи, имеющей опыт партнерств, над долей тех, кто состоит в браке, тогда как среди северокавказских респондентов соотношение обратное.

Для жителей Северного Кавказа доли женщин и мужчин, у которых наступило то или иное стартовое событие, ни для одного из событий не были значимо различными. В этом плане Северный Кавказ очень не похож на другие регионы России, где гендерные различия значимы как минимум на 98-процентном уровне для интимной близости, брака, деторождения, отделения от родителей, трудоустройства.

Межпоколенные различия оказались значимы по крайней мере на 97-процентном уровне и на Северном Кавказе, и в других регионах России как для мужчин, так и для женщин. Исключение составили вступление в первое партнерство (по нему для женщин Северного Кавказа межпоколенные различия статистически значимы только на 89-процентном уровне), а также окончание школы и завершение образования (межпоколенные различия не значимы ни для одной страты).

Изучение интенсивности наступления событий мы осуществили через анализ доли респондентов, совершивших стартовые события к сопоставимым возрастам (табл. 2). Для того чтобы сделать сопоставление поколений более объективным, мы попытались исключить главную помеху-неравенство шансов наступления событий у респондентов разных возрастов. Для этого мы посчитали для каждого поколения долю респондентов, у которых наступили интересующие нас события к конкретным возрастам: к 15, 20, 25, 30 и 35 годам. Самое младшее поколение мы наблюдаем пока только

1 Таблицы доступны по ссылкам: https://jsps.hse.ru/article/view/9737/10843; https://jsps.hse. ru/article/view/9737/10844; https://jsps.hse.ru/article/view/9737/10845; https://jsps.hse.ru/article/ view/9737/10846 
в двух точках - к 15 и 20 годам; респондентов 1985-1989 г.р.-в трех (15, 20, 25 лет), следующее поколение-в четырех (15, 20, 25, 30 лет), а два оставшихся поколения- на всех возрастных рубежах. Те категории, для которых различия между поколениями значимы как минимум на 97-процентном уровне, мы выделили черными прямоугольниками на графиках (табл. 2).

Время первой интимной близости и первого партнерства между поколениями изменяется мало, и, в основном, только для жителей Северного Кавказа, где наблюдается небольшое откладывание этих событий более молодыми поколениями по сравнению со старшими. Время первого брака и первого деторождения изменяется по поколениям сильнее: на Северном Кавказе между поколениями наблюдается разнонаправленная динамика, а в других регионах России более молодые поколения немного откладывают эти события по сравнению со старшими поколениями. По социоэкономическим событиям для Северного Кавказа наблюдается ряд тенденций, не зафиксированных в других регионах России. Так, для женщин Северного Кавказа доля отделившихся от родителей растет от более старших поколений к более молодым. Относительно первого трудоустройства для мужчин и женщин Северного Кавказа налицо прямо противоположные межпоколенные тенденции: мужчины более старших поколений трудоустраиваются интенсивнее, чем молодые, тогда как женщины-наоборот. При этом для молодых женщин рост интенсивности трудоустройств по сравнению с женщинами более старших поколений существенен. Можно предположить, что это начало нового тренда, связанного с большей трудовой активностью женщин.

\section{Возраст наступления событий}

Перейдем к анализу возрастов наступления событий посредством анализа медианных возрастов (табл. 3). Медианный возраст наступления событияэто возраст, который делит выборку пополам: у половины респондентов событие наступает раныше этого возраста, у половины- позже. Для оценки значимости различий медианных возрастов наступления каждого события между Северным Кавказом и другими регионами России мы использовали критерии Манна-Уитни и Колмогорова-Смирнова, а в разрезе региона и пола, а также региона, пола и поколений- критерий Краскала-Уоллиса.

Региональные и гендерные различия на 95-процентном уровне значимы только в медианных возрастах начала интимной жизни и трудоустройства: оба этих события наступают на Северном Кавказе позже, чем в других регионах России, причем как у мужчин, так и у женщин. Примечательно также, что у северокавказских женщин интервалы между социодемографическими событиями (различия между их медианными возрастами) значительно меньше, чем у мужчин Северного Кавказа, а также женщин и мужчин других регионов. Также северокавказские женщины впервые трудоустраиваются на год-два позже северокавказских мужчин. 


\section{Последовательность наступления событий}

Для выявления последовательности наступления стартовых событий мы вычислили для каждого респондента интервалы между датами наступления ряда событий, а затем посчитали медианные значения этих интервалов (табл. 4). Сопоставление интервалов между разными событиями по поколениям, полу и регионам позволяет отметить следующие наиболее заметные различия между Северным Кавказом и другими регионами России.

Все социодемографические события у жителей Северного Кавказа, особенно у женщин, наступают с очень маленькими интервалами, то есть идут практически друг за другом; у жителей других регионов России такая связанность наблюдается только для вступления в брак и деторождения. Меньший по сравнению с другими регионами России интервал между первой интимной близостью и зачатием на Северном Кавказе позволяет говорить о сохранении у северокавказского населения более традиционной модели семейной жизни, предполагающей интимную близость только в браке и не допускающей откладывания деторождения после создания семьи.

Сопоставляя интервалы между социоэкономическими событиями, важно отметить, что на Северном Кавказе больше интервал между завершением образования и первым трудоустройством. У северокавказских мужчин между этими событиями проходит около двух лет, у женщин-менее года, тогда как у остальных россиян- около трех месяцев. В промежутке между завершением образования и трудоустройством у северокавказских жителей, согласно медианным возрастам, происходит отделение от родителей и вступление в брак. У жителей других регионов России этот промежуток менее продолжителен и гораздо меньше наполнен стартовыми событиями.

Мужчины, живущие не на Северном Кавказе, сначала трудоустраиваются, а потом отделяются от родителей (интервал составляет три месяца). Остальные категории сначала покидают родительский дом, а потом выходят на работу: северокавказские мужчины и женщины из разных регионов- в течение четырех-пяти месяцев, а северокавказские женщиныв течение более чем года. У северокавказских женщин отделение от родителей происходит в основном одновременно со вступлением в брак. У северокавказских мужчин отделение от родителей происходит раньше, чем вступление в брак (особенно в молодых поколениях). У мужчин и женщин из других регионов чаще всего отделение от родителей также происходит до вступления в брак.

Рождение ребенка для всех респондентов, кроме северокавказских женщин младших поколений, чаще происходит после завершения образования и трудоустройства. Гендерные различия в этих интервалах больше, чем во всех остальных интервалах, и на Северном Кавказе они больше, чем в других регионах. У женщин между трудоустройством и рождением первого ребенка проходит на несколько лет больше, чем у мужчин, причем 
эта разница на Северном Кавказе составляет более 3,5 лет, а в других регионах - около 1,8 лет.

\section{Заключение}

Анализ данных исследования «Человек, семья, общество» позволил выявить ряд отличий между Северным Кавказом и другими регионами страны по характеристикам наступления стартовых событий в жизни мужчин и женщин. Во-первых, на Северном Кавказе действуют более традиционные модели перехода во взрослую жизнь, нежели в остальной России. Здесь по-прежнему брак остается более распространенной формой совместного проживания, чем партнерство (популярность которого увеличивается в других частях России). Социодемографические события наступают с очень маленькими интервалами, из-за чего получается, что первые дети у северокавказцев появляются в более молодых возрастах, нежели в других регионах, а старт интимной жизни и матримониальных союзов наступает в более поздних возрастах. Типичная последовательность наступления стартовых событий выглядит так: большинство респондентов всех регионов сначала получают образование, затем для жителей Северного Кавказа следует отделение от родителей и/или вступление в брак и только потом трудоустройство, а для жителей других регионов - сначала трудоустройство и/или отделение от родителей, а потом-вступление в брак. Деторождение для большинства респондентов во всех регионах происходит после вступления в брак.

Во-вторых, на Северном Кавказе гендерная разница в наступлении социодемографических событий выражена гораздо меныше, чем в остальных регионах России, но гендерная разница в наступлении социоэкономических событий присутствует там, напротив, значительно сильнее. Это подтверждает выводы других исследователей о гендерно дифференцированных жизненных сценариях на Северном Кавказе (Лыткина 2010; Хубиев 2008).

В-третьих, частота, возраст, интенсивность и очередность наступления событий у молодых поколений демонстрируют, что единая для всех норма перехода во взрослую жизнь заменяется разнообразием жизненных путей. Это хорошо видно на примере регионов России за пределами Северного Кавказа и начинает проявляться у северокавказских мужчин, тогда как северокавказские женщины продолжают демонстрировать довольно «традиционные» образцы поведения.

\section{Выражение признательности}

В данной научной работе использованы результаты проекта «Эффективность демографической политики: российский и международный опыт», выполненного в рамках Программы фундаментальных исследований НИУ ВШЭ в 2018 г. 


\section{Список источников}

Вишневский А.Г. (ред.) (2006) Демографическая модернизаџия России, 1900-2000. М.: Новое издательство.

Лыткина Т.С. (2010) Трансформация гендерного порядка: от традиции к современности. Опыт этносоциологического анализа северного Кавказа. Laboratorium. Журнал социиальных исследований, (3):96-125.

Хубиев Б. Б. (2008) Семья как социоченностная общность форм бытия человека. Автореферат диссертации докт. фил. наук. Нальчик: КБГУ.

Billari F. C., Hagestad G. O., Liefbroer A.C., Spéder Z. (eds.) (2005) The Timing of Life: The Organization of the Life Course in Europe. London: European Social Survey.

Billari F.C., Liefbroer A.C. (2010) Towards a New Pattern of Transition to Adulthood? Advances in Life Course Research, 15 (2): 59-75.

Buchmann M. (1989) The Script of Life in Modern Society: Entry into Adulthood in a Changing World. Chicago: University of Chicago Press.

Elder Jr. G.H., Johnson M. K., Crosnoe R. (2003) The Emergence and Development of Life Course Theory. In: J. T. Mortimer, M. J. Shanahan (eds.) Handbook of the Life Course. New York: Kluwer Academic / Plenum Publishers: 3-19.

Esping-Andersen G. (2007) Family Formation and Family Dilemmas in Contemporary Europe. Bilbao: Fundación BBVA.

Kaa D.J. van de (1987) Europe's Second Demographic Transition. Population Bulletin, (42):3-57.

Liefbroer A.C. (1999) From Youth to Adulthood: Understanding Changing Patterns of Family Formation From a Life Course Perspective. In: L.J.G. van Wissen, P. A. Dykstra (eds.) Population Issues. Dordrecht: Springer: 53-85.

Ekaterina Mitrofanova

\section{ENTERING ADULT LIFE: NORTH CAUCASUS IN COMPARISON TO OTHER REGIONS OF RUSSIA}

The goal of the paper is to present the currently available quantitative data on transitions to adulthood in the North Caucasus. Based on the results of the 2013 all-Russia survey 'Person, Family and Society', the North Caucasus is compared to other regions of Russia, with a special focus on the sociodemographic and socioeconomic events related to in the transition to adulthood. By sociodemographic events, we mean sexual debut, first partnership, first mar-

Ekaterina Mitrofanova- MA, Junior research fellow at the Institute of Demography, Lecturer at the Department of Demography, National Research University 'Higher School of Economics', Moscow, Russian Federation. Email: emitrofanova@hse.ru 
riage and first childbirth. Socioeconomic events include completing education, separation from parents, and gaining one's first employment. The quantum, timing, tempo and sequence of these events were compared for residents of the North Caucasus and of other regions of Russia born between 1970 and 1994. We discovered that in the North Caucasus the transition to adulthood follows a more traditional standard than in other regions of Russia. Specifically, in the North Caucasus the interval between marriage and birth of the first child is shorter; marriage is much more widespread than partnership; and childbearing takes place more intensively and at younger ages. Gender asymmetries in sociodemographic events are more pronounced in the North Caucasus than in other regions of Russia. Nevertheless, the data also shows certain demographic modernization in the North Caucasus. Thus, men (but so far not women) of younger generations show a larger variety of sequences of the events compared to elder generations, so that the obligatory norm for transition to adulthood is replaced by a variety of life paths.

Key words: transition to adulthood, marriage, childbirth, education, employment

DOI: 10.17323/727-0634-2019-17-1-133-141

\section{REFERENCES}

Billari F.C., Hagestad G.O., Liefbroer A.C., Spéder Z. (2005) The Timing of Life: The Organization of the Life Course in Europe. London: European Social Survey.

Billari F.C., Liefbroer A.C. (2010) Towards a New Pattern of Transition to Adulthood? Advances in Life Course Research, 15 (2): 59-75.

Buchmann M. (1989) The Script of Life in Modern Society: Entry into Adulthood in a Changing World. Chicago: University of Chicago Press.

Elder Jr. G.H., Johnson M.K., Crosnoe R. (2003) The Emergence and Development of Life Course Theory. In: J. T. Mortimer, M.J. Shanahan (eds.) Handbook of the Life Course. New York: Kluwer Academic / Plenum Publishers:3-19.

Esping-Andersen G. (2007) Family Formation and Family Dilemmas in Contemporary Europe. Bilbao: Fundación BBVA.

Kaa D.J. van de (1987) Europe's Second Demographic Transition. Population Bulletin, (42): 3-57.

Khubiev B.B. (2008) Sem' ja kak social'no-cennostnaja obshhnost' form bytija cheloveka [Family as the Social and Value Unity of Forms of Human Life]. PhD Thesis. Nal'chik: KBGU.

Liefbroer A.C. (1999) From Youth to Adulthood: Understanding Changing Patterns of Family Formation from a Life Course Perspective. In: L.J.G. van Wissen, P.A.Dykstra (eds.) Population Issues. Dordrecht: Springer: 53-85.

Lytkina T.S. (2010) Transformacija gendernogo porjadka: ot tradicii k sovremennosti. Opyt etnosocilogicheskogo analiza Severnogo Kavkaza [The Transformation of Gender Relations: From Tradition to Modernization. An Ethnosociological Analysis of the North Caucasus]. Laboratorium, (3): 96-125.

Vishenvski A.G. (ed.) (2006) Demograficheskaja modernizacija Rossii [The Demographic Modernization of Russia]. Moscow: Novoe Izdatel'stvo. 